\title{
Antibacterial and Antifungal Activities of Micromeria biflora (Leaves)
}

\author{
Muhammad Aurang Zeb ${ }^{1}$, Abdul Wahab ${ }^{3}$, Najeeb Ullah ${ }^{1,2 *}$, Abdul Jabbar ${ }^{2}$, Sunil Pandey ${ }^{4}$, Taj \\ Muhammad $^{5}$
}

${ }^{1}$ Department of Biochemistry, Hazara University, Manshera, Khyber Pakhtunkhwa, Pakistan

${ }^{2}$ Department of Chemistry, Kohat University of Science and Technology, Kohat, Khyber

Pakhtunkhwa, Pakistan

${ }^{3}$ Department of Pharmacy, Kohat University of Science and Technology, Kohat, Khyber

Pakhtunkhwa, Pakistan

${ }^{4}$ Department of Medical Microbiology, Nobel College, Pokhara University, Nepal

\section{$\underline{\text { ABSTRACT }}$}

Background: Herbal medicines have been practiced for thousands of centuries by tribes all over the world. We aim to study extraction, fractionation, antibacterial and antifungal activity of Micromeria biflora.

Methodology: Sample was washed properly with de-ionized water, solvents used (i.e. chloroform, ethyl acetate, n-hexane and methanol) were filtered and added. Some amounts of dehydrated reagents to purify the solvents before using. Shad dried plant powder was chopped and soaked in methanol for 10 days Dimethyl sulfoxide (DMSO) was used as solvent because it did not show any activity against bacteria and also it possess polar and non-polar groups therefore, in dimethyl sulfoxide most of the polar and non-polar compounds are soluble. The antibacterial bioassay was done by Agar Well Diffusion method, by measuring the zone of inhibition against the test microorganisms. Two fungal strains i.e. Alternaria, Fusariumoxysporium were used for antifungal activities.

Results: At $5 \mathrm{mg} / \mathrm{mm}$ the detailed spectrum of antibacterial activity of various fraction i.e. n-hexane, chloroform, ethyl acetate, and methanol was determined. All fractions showed activity against fungal species. Highest activity was shown by Chloroform fraction against Fusariumoxysporium giving wider zone of $10.2(\mathrm{~mm})$. Ethyl acetate fraction against Alternaria was very less active giving lowest value of $5.9(\mathrm{~mm})$.

Conclusion: The results of antibacterial activity revealed that methanol show highest activity among all fractions against salmonella Typhi. The methanol extract of Micromeria biflora gave the widest zone of inhibition (16.1 mm) against salmonella Typhi using agar well diffusion. The results therefore established a good support for the use of Micromeria biflora in traditional medicine.

Keywords: Herbal Medicines, Micromeria biflora, Antibacterial, Antifungal, Agar, Diffusion Method

\section{BACKGROUND}

Herbal medicines have been practiced for thousands of centuries by tribes all over the world. From the earliest times until the end of nineteenth century plants are still the common source of medicinal treatment yet.

*Correspondance: Najeeb Ullah

Department of Chemistry, Kohat University of Science and Technology, Kohat, Khyber Pakhtunkhwa,

PakistanE-mail: Najeebullah73@gmail.com
During the twentieth century, this vast body of knowledge has been swept aside in favor of the mass produced chemical medicines, which while saving countless lives in certain fields, have not proved to be the universal panacea that researchers had hoped for. Now again the researchers are interested into medicinal plants in their chemistry because most of the plants have started widely used for foods therapeutic purposes. As a result of increasing use of alternative system of medicines in the recent years the 
herbal medicines market has rapidly grown. Using natural, plant-derived medicines that are "healthier" then prescription drugs derived from synthesized products is something appeals to consumers [1-3] incorrect use of conventional synthetic medicine may result in side effect and other problems. Moreover, a large percentage of the world's populations don't have access to conventional pharmacological treatment, and further more "natural" products are harmless. Synthetic medications are expensive and government regulations require that their adverse effects be clearly enumerated. Patients perceive herbal remedies as inexpensive and associated with mild side effects. Herbal products are readily available and offer patients degree of autonomy in health care choice. Conclusively, the herbal products market Expansion is because aggressive marketing, due to low cost, minimal regulatory control, easy access and a belief that because herbal products are "natural" they are safe [4]. The herbal remedies now a day societies have become more popular in the treatment of minor ailments, and also because of increasing cost of personal health maintenance. Indeed, market and public demand has been so great that there is a great risk that many medicinal plants today, face either overexploitation or loss of genetic diversity. More than $50 \%$ of all drugs in clinical use have natural origin. Of the world's 25 best-selling pharmaceutical agents, 12 are natural products derived [5-7]. Natural products continue to play in important role in drugs discovery programs of the pharmaceutical industry and other research organization. More than 600 botanical items have been recognized in various editions of the United States Pharmacopeia. During the last century various modern procedures have been adopted for the determination of biological activities of the plant extracts and identification of active principals, especially chromatography, spectroscopic, and high throughput bioassay techniques. Research in this direction has been greatly facilitated by the use of modern physio-chemical techniques of isolation in structure elucidation [8-10]. The importance of medicinal plant is the source of active drugs which is emerged from chemical profile that produces specific physiological action on biological system. Compounds like flavonoid, alkaloid, tannin, and phenolic compounds of plant $[11,12]$. All the solvents used (i.e. chloroform, ethyl acetate, n-hexane and methanol) were filtered and added some amounts of dehydrated reagents ( $\mathrm{MgSO} 4, \mathrm{Na} 2 \mathrm{SO} 4)$ to purify the solvents before using.

\section{METHODOLOGY}

\section{Collection and drying of Plant materials}

Sufficient quantity of Micromeria biflora plant was collected in March 2014 from Malakand Division Khyber Pakhtunkhwa Pakistan in flowering season (Figure 1). Plant was identified by the faculty of department of botany, Kohat University of Science and Technology, Pakistan. The sample was washed properly with de-ionized water for removing dirt, dust and other possible impurities. The plant was washed and dried at room temperature for fifteen days and then crushed into coarse powder using grinder and then stored in clean, dried plastic bags for further processing. The plant species was authenticated by the herbarium staff of Botany Department, Kohat University of Science and Technology and were kept in laboratory for further processing.

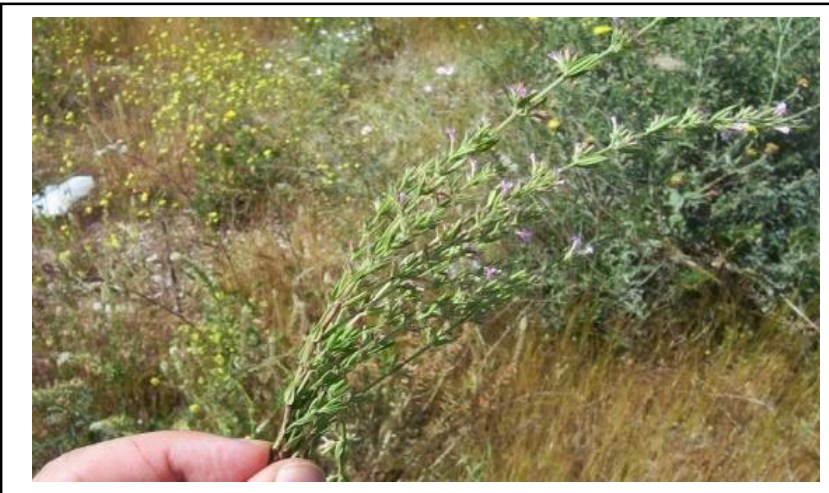

Fig. 1. Micromeria biflora 


\section{Solvent used in experimental works}

All the solvents used (i.e. chloroform, ethyl acetate, nhexane and methanol) were filtered and added some amounts of dehydrated reagents $(\mathrm{MgSO} 4, \mathrm{Na} 2 \mathrm{SO} 4)$ to purify the solvents before using.

\section{Extraction of crude}

The shad dried plant powder was chopped and soaked in methanol for 10 days. Then shake the solution 15 times a day to dissolve the plant material in methanol. The filtrate was evaporated under reduced pressure by using Vacuum Rotary Evaporator keeping the temperature at $40^{\circ} \mathrm{C}$ to give crude extracts. Extracts was made dried and weighed.

\section{Fractionation of crude extract}

The crude extracts of Micromeria biflora was further suspended in water and partitioned successively with $\mathrm{n}$-hexane, chloroform and ethyl acetate for obtaining $\mathrm{n}$ hexane-soluble, chloroform-soluble, ethyl acetate-soluble and aqueous soluble fractions respectively. From each fraction the corresponding solvent was evaporated by rotary evaporator keeping specific temperature for each solvent. By this method, gummy residue of each fraction was obtained.

\section{Preparation of stock Solution}

Each fraction i.e. n-hexane, chloroform, ethyl acetate and methanol frictions were dissolved in Dimethyl Sulfoxide (DMSO) in ratio of $5 \mathrm{mg} / \mathrm{ml}$. Dimethyl Sulfoxide (DMSO) was used as solvent because it did not show any activity against bacteria and also it possess polar and non-polar groups therefore, in Dimethyl Sulfoxide most of the polar and non-polar compound are soluble. That's why it was selected for antibacterial and antifungal activities. The crude extracts and subsequent solvents soluble fractions were then subjected to antimicrobial and antifungal activities.

\section{Bacterial Strains}

Four bacterial strains Salmonella Typhi, Staphylococcus aureus, Escherichia coli, and Streptococcus spp were used. These bacteria were cultured on nutrient broth (Oxoid) at $37^{\circ} \mathrm{C}$ for 24 hours.

\section{Antibacterial Activity}

In this study, various extracts of Micromeria biflora were subjected for antibacterial activities against gram positive and gram negative strains. The bacterial strains such as Escherichia coli, Staphylococcus aureus, Salmonella Typhi and Streptococcus spp were tested by disc diffusion Susceptibility Method. All these microorganisms were obtained from the department of Microbiology KUST.

\section{Preparation of media}

Media of nutrient agar was prepared in conical flask accordance to the directions provided by the manufacturer. The media along with the Petri dishes, pipette and metallic rod were sterilized in autoclave for 15 minutes at $121^{\circ} \mathrm{C}$ and 15 psi pressure. The media were then poured into Petri dishes under aseptic condition (Laminar flow hood) and let them for solidification for about 25 minutes.

\section{Antibacterial Bioassay}

The antibacterial bioassay was done by Agar Well Diffusion Method, by measuring the zone of inhibition against the test microorganisms.

\section{Well assay method}

After solidification of media Wells of $6 \mathrm{~mm}$ were dug in media by using sterile plastic borer. Each well was given a specific number. Bacterial culture corresponding to 104 to $106 \mathrm{CFU}$ (colony forming unit) was inoculated/streaked on the surface of the solidified media. Stock solutions of crude extracts and each fraction in DMSO at concentration of $5 \mathrm{mg} / \mathrm{mL}$ were prepared from stock solution was added 
into respective wells. Petri dishes were then kept in incubator at $37^{\circ} \mathrm{C}$ for incubation. The zones of inhibition were measured after 24 hours of incubation. Ciprofloxacin was used as standard and as a positive control while DMSO was used as used as a negative control. The zones of inhibition of crude extracts, n-hexane, chloroform, and ethyl acetate and water fractions were compared with zones of inhibition of standard drugs ciprofloxacin. The amount of each growth well was measured.

\section{Antifungal Activity}

Two fungal strains i.e. Alternaria, Fusariumoxysporium were used for antifungal activities. Nutrient broth of concentration $13 \mathrm{~g} / \mathrm{L}$ in distilled water was used to refresh the fungal strains. Four flasks of $250 \mathrm{ml}$ were filled with broth and sterilized in autoclave. The fungal colonies were inoculated to each flask separately. The flasks were place in incubator at $30^{\circ} \mathrm{C}$ for 3 days for refreshing fungal Strains. In $500 \mathrm{ml}$ conical flask 14 grams of nutrient agar was taken and dissolved in $500 \mathrm{ml}$ of distilled water. The flask was autoclaved at $121^{\circ} \mathrm{C}$ for 15 minutes at 1.5 pounds pressure. About $9 \mathrm{ml}$ of medium was added to clean, dry and sterilized test tubes. Solutions of crude extracts and fractions were prepared each of $5 \mathrm{mg} / \mathrm{ml}$ concentration. One $\mathrm{ml}$ of sample $(5 \mathrm{mg} / \mathrm{ml})$ was also added to test tube, the test tube was kept in inclined position to make a slant.

\section{RESULTS}

\section{Result of antibacterial activity (Result at 5mg/ml)}

In this study, the detailed spectrum of antibacterial activity of various fraction i.e. n-hexane, chloroform, ethyl acetate, and methanol was determined. The zones of inhibition formed by the fraction crude are given in (Table 1 and Figure 2).

The crude extract was active against all bacterial species but showed more antibacterial activity against Salmonella Typhi, Streptococcus and Staphylococcus aureus while it showed less activity against $E$. coli. The n-hexane fraction give wider zone of inhibition against Streptococcus but it exhibited less activity against $E$. coli. The chloroform fraction was very effective against Staphylococcus aureus, Streptococcus while it had less activity against E. coli. The ethyl acetate fraction showed good activity against Salmonella Typhi but less activity against Streptococcus and Staphylococcus aureus. The aqueous solution was highly active against Salmonella Typhi, Streptococcus but less active against E. coli and Staphylococcus aureus.

\section{Table 1. Antibacterial activity of Micromeriabiflora}

\begin{tabular}{|c|c|c|c|c|c|c|}
\hline \multirow{2}{*}{$\begin{array}{l}\text { Microorganisms } \\
\text { (bacterial strain) }\end{array}$} & \multicolumn{6}{|c|}{ Zone of inhibition (mm) } \\
\hline & $\begin{array}{c}\text { Methanol } \\
\text { fraction crude } \\
5 \mathrm{mg} / \mathrm{ml}\end{array}$ & $\begin{array}{c}\text { n-hexane } \\
\text { Fraction } \\
5 \mathrm{mg} / \mathrm{ml}\end{array}$ & $\begin{array}{c}\text { Chloroform } \\
\text { Fraction } \\
5 \mathrm{mg} / \mathrm{ml}\end{array}$ & $\begin{array}{c}\text { Ethyl Acetate } \\
\text { Fraction } \\
5 \mathrm{mg} / \mathrm{ml}\end{array}$ & $\begin{array}{c}\text { Aqueous } \\
\text { fraction } \\
5 \mathrm{mg} / \mathrm{ml}\end{array}$ & $\begin{array}{c}\text { Standard Drug } \\
\text { Ciprofloxacin } \\
(30 \mu \mathrm{g})\end{array}$ \\
\hline Salmonella Typhi & 16.1 & 11.0 & 10.5 & 13.2 & 8.3 & 20.5 \\
\hline S. aureus & 12.5 & 9.4 & 13.0 & 10.1 & 6.8 & 19.6 \\
\hline Streptococcus & 13 & 12.2 & 11.6 & 9.9 & 7.2 & 21.9 \\
\hline Escherichia coli & 8.3 & 9.0 & 9.8 & 11.1 & 5.9 & 22.0 \\
\hline
\end{tabular}




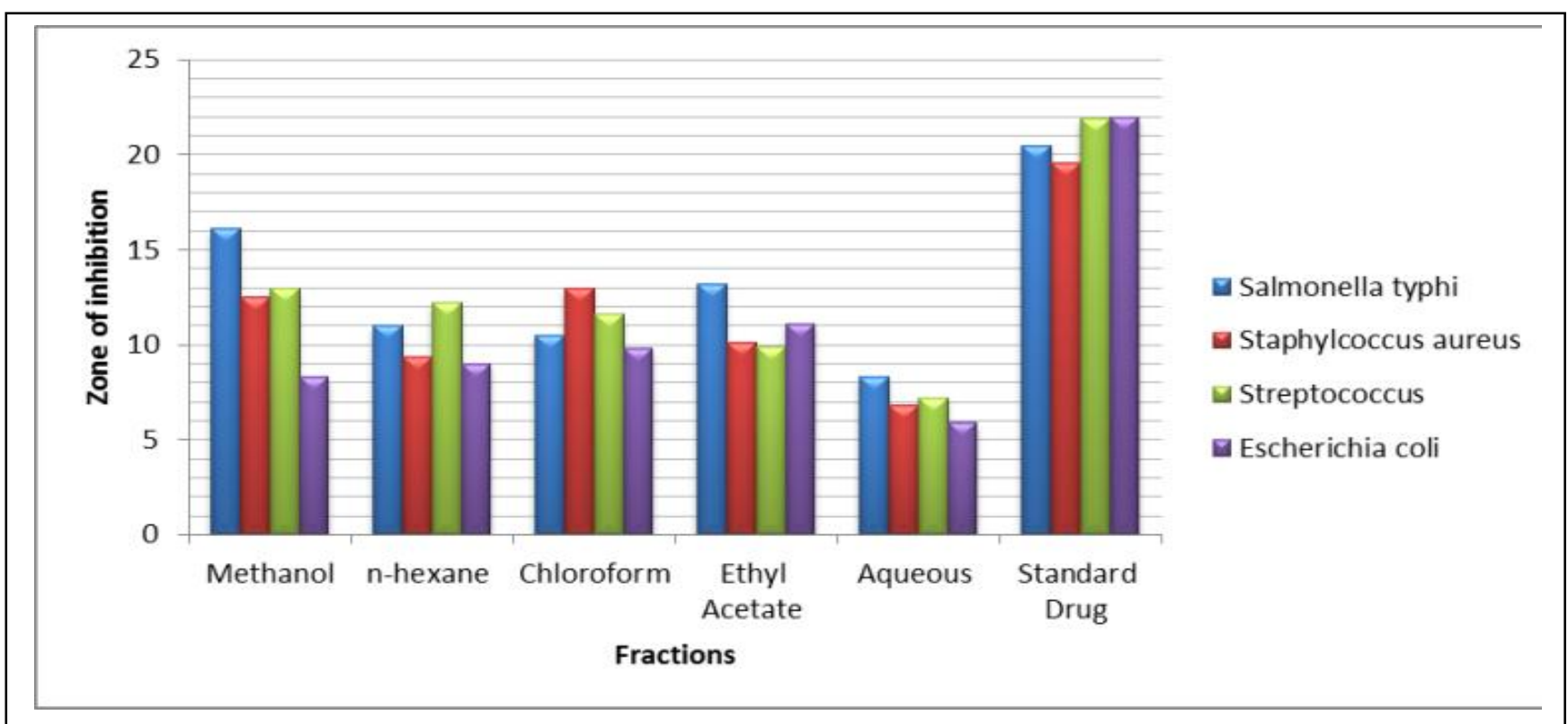

Fig. 2. Graphical representation of antibacterial activity of Micromeriabiflora.

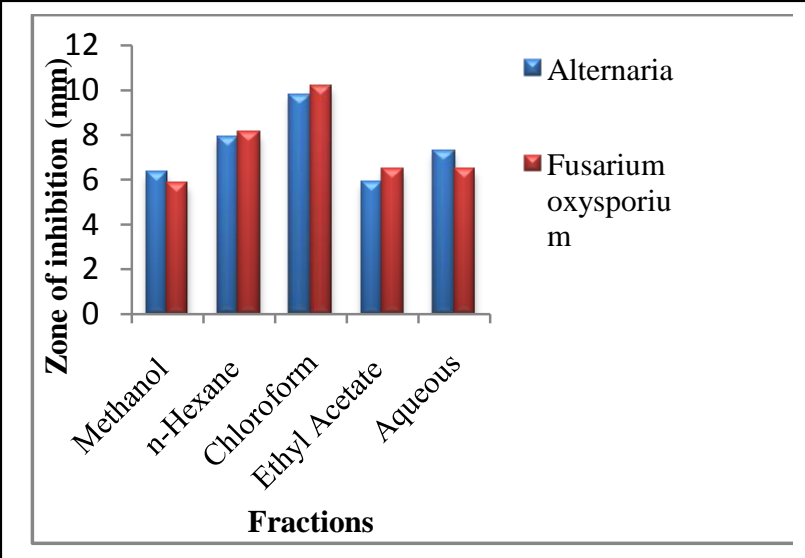

Fig. 3. Graphical representation of antifungal activity of Micromeriabiflora

\section{Results of Antifungal activity (Results at $5 \mathrm{mg} / \mathrm{ml}$ )}

In this study, there was determined the antifungal activity of five different fractions of Micromeria biflora. (Table 2 and Figure 3). All fractions showed activity against fungal species. Highest activity was shown by Chloroform fraction against Fusariumoxysporium giving wider zone of $10.2(\mathrm{~mm})$. Ethyl acetate fraction against Alternaria was very less active giving lowest value of $5.9(\mathrm{~mm})$.

Table 2. Antifungal Activity of Micromeriabiflora.

\begin{tabular}{|ccccccc}
\hline $\begin{array}{c}\text { Microorganisms (Fungal } \\
\text { strains) }\end{array}$ & \multicolumn{3}{c}{ Zone of inhibition $(\mathbf{m m})$} \\
& Methanol & n-Hexane & Chloroform & Ethyl Acetate & Aqueous \\
& Fraction & fraction & Fraction & Fraction & Fraction \\
Alternaria & 6.3 & 7.9 & 9.8 & 5.9 & 7.3 & 6.5 \\
Fusariumoxysporium & 5.8 & 8.1 & 10.2 & 6.5 & \\
\hline
\end{tabular}




\section{DISCUSSION}

Natural alternative treatments for fungal and bacterial infection may provide a pathway for the development of new antimicrobial agents. This study indicated that all the four fraction (aqueous, methanol hexane, chloroform and ethyl-acetate extracts) of Micromeria biflora was more potent against both the Gram-positive and Gram-negative bacteria and also against two fungal strains. This study emphasizes that the medicinal plant Micromeria biflora, is active against hospital strains of, Escherichia coli, Staphylococcus aureus, Salmonella Typhi, Streptococcus and some fungal strains. However, this finding was consistent on repeated experiments and warrant further investigation. Inhibition zone sizes that were obtained that support the finding of the well diffusion method. Since the activity was demonstrated in all extraction, they indicate a potential source of antimicrobial agent and should be studies further. Further studies will determine what compounds are active in the various extracts. However, extracts of Micromeria biflora may be a target for investigation since it has been shown to contain compound with bioactivity. The bioactive compounds may not be limited to those already identified.

The plant crude extract and all sub fractions (n-hexane, chloroform, ethyl acetate, methanol and aqueous) were subjected to antibacterial activities and antifungal activity. For antibacterial activities four bacterial strains Salmonella Typhi, Streptococcus, Escherichia coli and Staphylococcus aureus were used in antibacterial assay. For antifungal activity two fungi: Fusariumoxysporium and Alternaria were used in antifungal assay. These activities are determined by using agar well diffusion methods. The growth of four bacterial isolates was inhibited by five extracts. Similarly, the growth of two test fungi was inhibited by all the five extracts. Highest activity fraction was chloroform which give wide zone of $(10.2 \mathrm{~mm})$ against Fusariumoxysporium.

\section{CONCLUSION}

Medicinal plants are commonly used for treating various diseases among these plants one is Micromreria biflora. Our study describes the extraction, fractionation and antibacterial activity of Micromeria biflora. The results of antibacterial activity revealed that methanol show highest activity among all fractions against Salmonella Typhi. The methanolic extract of Micromeria biflora gave the widest zone of inhibition $(16.1 \mathrm{~mm})$ against Salmonella Typhi using agar well diffusion. The results therefore established a good support for the use of Micromeria biflora in traditional medicine.

\section{COMPETING INTERESTS}

We declare that we donot have competing of interest.

\section{ACKNOWLEDGEMENTS}

We are grateful to Dr. Abdul Wahab, Chairman Department of Pharmacy, Kohat University of Science and Technology for his constant inspiration and technical support.

\section{REFERENCES}

1. Rates SM. Plants as source of drugs. Toxicon. 2001 May 31; 39(5):603-13.

2. Vaulto A. G, Smet P. A .G. M, Dukes M .M. G. Drugs used in non-orthodox medicine. In: Meyer's Slide Effect of Drugs. 11thed. Elsevier: Amsterdam; 1998.

3. Fennell CW, Lindsey KL, McGaw LJ, Sparg SG, Stafford GI, Elgorashi EE, Grace OM, Van Staden J. Assessing African medicinal plants for efficacy and safety: pharmacological screening and toxicology. Journal of Ethnopharmacology. 2004 Oct 31; 94(2):205-17.

4. S. J. Wort. Agency for Healthcare and Research and Quality (AHRQ) Evidence Reports 1-60", Health 
5. Technology Advisory Committee-Minnesota (static collection), National Library of Medicine; 2000

6. Gibson VC, Spitzmesser SK. Advances in nonmetallocene olefin polymerization catalysis. Chemical reviews. 2003 Jan 8; 103(1):283-316.

7. Kinghorn AD, Balandrin MF. Human medicinal agents from plants. American Chemical Society (ACS); 1993.

8. O'Neill MJ, Lewis JA. The renaissance of plant research in the pharmaceutical industry. InACS symposium series (USA) 1993.

9. Kinghorn AD, Balandrin MF. Human medicinal agents from plants. American Chemical Society (ACS); 1993.

10. Berdy J. Bioactive microbial metabolites. The Journal of antibiotics. 2005 Jan 1; 58(1):1-26.

11. Balandrin NF. Human medicinal agents from plants kinghorn. InACS symposium series 1993 (Vol. 534, pp. 2-12).

12. Choudhary MI, Parveen Z, Jabbar A, Ali I.

Antifungal steroidal lactones from

Withaniacoagulance. Phytochemistry. 1995 Nov $30 ; 40(4): 1243-6$.

13. Pego JV, Kortstee AJ, Huijser C, Smeekens SC.

Photosynthesis, sugars and the regulation of gene expression. Journal of Experimental Botany. 2000 Feb 1; 51(suppl 1):407-16.

\section{Article History}

Received: 09 July 2015

Accepted: 05 October 2015

Published online: 15 October

\section{For citation:}

Zeb MA, Wahab A, Ullah N, Jabbar A, Pandey S, Muhammad T. Antibacterial and Antifungal Activities of Micromeria Biflora (Leaves).International Journal of Medicine \& Biomedical sciences. 2015; 1(1):28-34 